\title{
Smart electric storage heating and potential for residential demand response
}

\author{
Sarah J. Darby (iD
}

Received: 30 November 2016/Accepted: 14 July 2017

C) The Author(s) 2017. This article is an open access publication

\begin{abstract}
Low-carbon transition plans for temperate and sub-polar regions typically involve some electrification of space heating. This poses challenges to electricity system operation and market design, as it increases overall demand and alters the temporal patterns of that demand. One response to the challenge is to 'smarten' electrical heating, enabling it to respond to network conditions by storing energy at times of plentiful supply, releasing it in response to customer demands and offering rapid-response ancillary services to the grid. Shared operation of domestic electrical heating, in such a scenario, may imply changes in everyday heating practices and will change the number of system stakeholders, their activities and how they relate to each other.

This paper sets out some practical and theoretical issues relating to the potential for residential demand response via electric storage heating, drawing on academic and policy-related literature and on material from a current research project. It offers a brief history of residential storage heating and recent developments, paying particular attention to customer experience; considers the role of distributed storage in energy transitions and associated questions of value; outlines how agency and value in a smart system may be distributed between
\end{abstract}

\footnotetext{
S. J. Darby $(\bowtie)$

Environmental Change Institute, Oxford University Centre for the Environment, South Parks Road, Oxford OX1 3QY, UK e-mail: sarah.darby@eci.ox.ac.uk URL: http://www.eci.ox.ac.uk/research/energy/index.php
}

stakeholders; and assesses continuity and change in storage heating. While the paper focuses on storage heating, many of the issue raised apply to heat pumps, given their functional similarities with storage heaters and water heaters. The paper concludes with some conditions to be met if smart storage heating is to succeed in the twin tasks of providing effective customer service and demand response, and sets out questions for further research into demand response and heating practices.

Keywords Electrical storage heating - Smart energy Socio-technical system $\cdot$ Demand response $\cdot$ Distributed storage $\cdot$ Load control

\section{Energy transitions and the electrification of heating}

The future of heating will strongly influence the scale and shape of electricity demand in regions with cold winters, and there is an important set of decisions to be made about ways of providing heating services, especially in countries that rely heavily on fossil fuels for this (Eyre and Baruah 2015). These decisions will be informed by estimates of heat demand (strongly related to building efficiency in retaining heat and social comfort practices) and the extent to which electric heating appliances can be controlled to match supply availability and network conditions, without customers suffering discomfort or excessive costs.

The main options for electrifying residential heating ${ }^{1}$ are heat pumps and resistive heating, with or without 
storage (Maclean et al. 2016). In terms of system-wide objectives, heat pumps are attractive in terms of end-use efficiency, offering running costs comparable to those for gas heating and making smaller demands on the system than would be made by resistive heating with the same output. Even so, $100 \%$ adoption of heat pumps globally, without improving building efficiency, could increase peak demand by an estimated $65 \%$ and raise the electricity peak: mean demand ratio from $\sim 1.6$ to 2.1 (Fawcett et al. 2015). Reducing and containing overall electricity demand remains a priority, even with the most efficient heating technologies available.

Heat pumps have relatively high capital and installation costs and can be unsuited to small dwellings because of the space they require. Resistive heating, by contrast, offers relatively low capital outlays and is simple to install. While it is best suited to homes with low heat loads - small and well-insulated - a high penetration of resistive heating, especially if installed in inefficient, high-consuming buildings, risks overloading any electricity system - considerably more so than heat pumps. The main drawback to any resistive heating is thus the sheer scale of demand. Resistive storage heaters, though, do have the advantage that they operate primarily on off-peak electricity, bringing down costs to customers and to the system. Hence the recommendation that priorities for Great Britain should be to replace on-peak by off-peak (storage) electric heating and old inefficient water and storage heaters by new ones; also to encourage development of a supply chain and market in automatable, controllable load 'with a focus on giving customers the heating systems they may want/prefer' (Sustainability First 2014, p.21).

\section{The introduction and use of electric storage heating}

An electric storage heater uses electrical resistance elements to heat high-density bricks in an insulated casing. This has traditionally happened overnight, when demand and the cost of generation have been low; the stored heat then discharges gradually into the space around it over the course of the day. The heaters are

\footnotetext{
${ }^{0}$ This paper concentrates on space heating because of important and often complex issues with regard to comfort and control, and the scale and timing of demand. However, many of the considerations are also applicable to electric water heating.
}

normally used in conjunction with a basic night/day time-of-use tariff. First developed in air-raid shelters in London in the 1940s and adopted soon afterwards in Austria, Switzerland and Germany (Asbury and Kouvalis 1976; Carlsson-Hyslop 2016), such storage heating has been offered as a basic form of demand response in several countries with winter-peaking electricity systems, increasing the profitability of generating plants by absorbing their output overnight and reducing the need for investment in capacity to cover peak demand during the day.

Storage heating adoption is influenced by a mix of physical, systemic and social reasons factors such as climate, building type, tenure, energy supply infrastructure and regulatory environment. For example, storage heaters can offer an alternative to oil or solid fuel in areas without access to piped gas or district heating; they will offer more value in regions with a high proportion of inflexible supply; and they may be considered particularly suitable for apartment blocks and rental properties for reasons of upfront cost, safety and maintenance needs: in Great Britain, 25\% of apartments are electrically-heated, compared with only $4 \%$ of houses (Ofgem 2015). It follows that residential storage heating is likely to be concentrated among particular social groups. For example, British customers who rely on it as their main source of heating are more likely to have lower incomes, live in private rented accommodation and belong to the youngest or oldest age groups (Consumer Focus 2012; Ofgem 2015).

In some countries with winter-peaking demand, storage heating has accounted for a substantial slice of the market: roughly a fifth of domestic electricity in the UK in 2012 was supplied during off-peak hours, much of it for storage heating and water heating, while approximately 1.7 million residential customers (6-7\% of the total) were using storage heaters as their primary source of warmth, providing a substantial resource for the electricity system (Frontier Economics and Sustainability First 2014; BEIS 2016). The manufacturer of UK storage heaters has estimated that they already offer over four times as much storage capacity as is available through the country's pumped hydro schemes (Frontier Economics and Sustainability First 2014), while a consultancy study indicates that if all suitable residential storage heaters and cylinders in the EU-27 were replaced by smart-enabled equipment, the storage potential would similarly be almost four times that in 'installed' storage capacity in the EU-27, primarily pumped hydro (DNV KEMA 2013). 
This actual and potential smart storage, of course, is only usable for heating, which is far from ideal in thermodynamic/exergy terms, and it can only be stored for relatively short periods: even well-insulated new-generation storage heaters will lose at least a quarter of their stored heat within $24 \mathrm{~h}$ through uncontrolled losses if not recharged (Clarke et al. 2013 plus Dimplex Quantum technical specification 2013).

Storage heating is unusual as a network resource in that the utilities benefiting from the service it provides do not usually invest in the heaters themselves: these distributed assets are owned by the people who use them, or by their landlords. However, management of the heating appliances is shared between utility and customer. With traditional/non-smart storage heaters, customers may adjust controls on the heaters to switch off, reduce input or output, and 'boost' heating during the day, but the heaters charge up overnight by remote control, usually a 'ripple' control to avoid sudden surges in demand. With a new generation of storage heaters, control continues to be shared but the possibilities are enlarged, as discussed below.

\section{Recent developments in storage heating}

A new generation of storage heating appliances is now on the market, better insulated than earlier models, slimmer and with more sophisticated controls. ${ }^{2}$ Some of these heaters are being further adapted with the addition of smart electric thermal storage (SETS) technology and this is being tested in a series of research projects (see below). The control element allows for seven-day programming of room heaters to meet anticipated needs in terms of temperature and timing, either through 'onboard' controls on the devices themselves or remotely via apps.

There is also now the potential to make storage heating more responsive to system conditions around the clock. With the addition of smart meters, able to take readings at frequent, regular intervals, it is possible to record usage at different rates for agreed time periods so that, for example, heaters can be charged at any time of

\footnotetext{
$\overline{2}$ Operating instructions for such a heater can be seen at http://www.glendimplexireland.com/assets/kb/operating instructions/0/Quantum_Operating_Instructions_Issue_5_Series_D. pdf
}

day when system conditions are favourable and not just overnight or (expensively) when customers use the 'boost' function at other times of day. An aggregator, who may be the electricity supplier or a third party, could charge up a set of heaters and water cylinders mid-afternoon, if abundant solar or wind energy is available, or to switch them off and on for brief periods in order to provide a fast response to the ancillary services market.

These more dynamic services are typically more valuable to the system operators than peak demand reduction through static time-of-use price signals, but they do pose a challenge for monitoring and verification, especially where very short responses are concerned. The heaters can therefore only offer some forms of value to customer and system if they operate within a system of metering, verification, settlement and billing that supports dynamic response.

A second major consideration is that the system operator needs to be able to charge up or switch off aggregated heaters in order to meet system needs at any time of day, within the temperature and timing parameters set by customers: such an arrangement should work for both utility and user. Customer experiences and expectations of storage heating, and their ability to manage it, are therefore significant.

\section{Customer experiences of storage heating}

Traditional storage heating has not offered the rapidresponse control possible with central heating radiators, gas fires or standard electric resistance heaters. Storage heater users have typically been able to perform three operations to control their heating:

(a) set the input control for the level of charge each night (that is, on the day before they will be using any stored heat and, ideally, making use of weather forecasts to estimate input requirements);

(b) adjust the output control to govern the speed at which heat is released over the following day;

(c) use a 'boost' control for extra heat in the course of the day. This may come from accelerated release of stored heat, with the aid of a small fan in the heater. But if the stored heat has been exhausted (more likely to occur in poorly-insulated housing), the boost will come from additional resistance heating. Boost controls offer rapid response but are 
expensive for customers who have to pay at peaktime rates; boosting also adds to system operator difficulties by increasing demand at times of day when it already tends to be high.

People in inadequately-insulated homes who spend most of their time at home in the late afternoon and evening are especially likely to struggle to achieve affordable warmth if they rely primarily on storage heating (Bouzarovski and Petrova 2015; Ofgem 2015). Investment in insulation is likely to be the most effective long-term measure but may not be an option for many tenants and low-income households.

Difficulties with slow-response control help to explain why only $68 \%$ of a sample of British households with storage heating surveyed in 2012 said they were satisfied with it (compared with $91 \%$ of respondents with gas central heating), while $25 \%$ were dissatisfied (Consumer Focus 2012). An earlier survey of British public opinion on energy issues found storage heating the least popular option for shifting electricity load (water heating was the most popular), although younger respondents were more likely to show an interest in adopting storage heating than the older ones. Scottish respondents - that is, those from the coldest regions of the country-were the least enthusiastic (IpsosMORI 2010). There is a widely-shared view among British storage heater users that more information and advice could help with management (Ofgem 2015), and simple guides to usage have proved popular. ${ }^{3}$

This very brief look at customer experience of storage heating shows how, although it offers relatively inexpensive heating for those who have to rely on electricity, it has been difficult to control and not very effective at releasing heat when needed. If it is installed in poorly-insulated homes of people who are tenants and/or on low incomes, customer experiences are even less likely to be positive. This dissatisfaction may be at least as much due to the housing as the heating.

Clearly, new-generation storage heaters will need to address customer needs in order to be marketable. Can new designs and 'smart' controls alter acceptability? If it is difficult to manage basic, unsmart storage heaters, will more complex and sophisticated controls lead to a better service for customers or one that is more difficult to understand and operate? It is reasonable to expect that

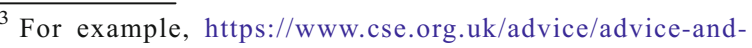
support/night-storage-heaters
}

outcomes will be affected by the design of appliances and customer interfaces, by characteristics of the customers themselves and their homes, and by the availability of guidance before, at and after installation (Darby et al. 2015; Wade et al. 2016). Hence the need to test new technology in a range of conditions, including those relating to transfer of knowledge and know-how.

A further question relates to whether smart storage heating might affect heating practices in the home. Is it effectively neutral in terms of user activity, so that customers only have to set their preferences for temperature and timing, and the technology will do everything else? Or does smart storage necessarily involve changes in how people go about the business of keeping warm and comfortable? Before discussing this, the following sections examine some wider issues of demand-side response and the value of smart storage to stakeholders in different circumstances.

\section{Demand-side response and distributed storage in energy transitions}

Electricity systems must continually balance supply with demand. Traditionally, supply has been adjusted to meet demand through 'dispatchable' forms of generation, especially fossil fuels and hydropower. As the proportion of supply from wind and sun increases, there is a transition from demand-led to supply-led systems, in which demand must fit with whatever supply is available at a given time. The potential role for demand in system balancing - demand response-increases, because it is more economical than the alternative of building new 'peaking capacity' that will, by definition, only be used for short periods of time. Storage occupies a special and potentially critical position in supply-led systems, because it can operate as both demand (soaking up energy when it is readily available) and supply (releasing it at times of less abundance and higher cost). While storage has to be accounted for as net demand in energy terms, due to energy losses during storage, it may have considerable monetary value at particular times if it allows energy services to continue when they would otherwise come to a halt.

It may be worth saying a little about the terms 'demand' and 'demand response' at this point. While 'demand' may simply refer to electricity usage as far as the user/customer is concerned, from the perspective of the supply industry it can refer to any activity on the 
customer side of the meter. Therefore demand response may be provided by load-shifting or onsite storage or onsite generation such as rooftop solar PV: all could lessen the demand for electricity from the grid. As well as coming from different technical configurations and activities, demand response may also operate on a variety of timescales in order to meet system needs for balancing. A recent annual report on demand response in Great Britain gives a useful overview of various services and markets for demand response, such as peak avoidance, frequency response, demand turn-up and fast reserve (National Grid 2016).

Historically, demand response has been carried out by high-consuming industrial customers with contracts requiring them to switch off equipment for specified periods of time when the power system is under-supplied. Now, the more widespread availability of interval metering makes it possible to distribute demand response among smaller customers as well: their consumption can now be measured in half-hourly or smaller segments and billed in ways that reflect the cost of supply at a given time with the generation mix available at that time. If these charges become more cost-reflective, the argument goes, customers will respond in various ways. They may do so very directly, by switching equipment on and off manually, or may programme their appliances to respond to signals, e.g. when unit prices rise above a specified level, as long as this does not interfere with particular energy service requirements; or they may agree to some degree of direct load control by an external body (Saele and Grande 2011; Darby and McKenna 2012; Goulden et al. 2014). Loss of personal control over domestic equipment is a matter of concern to many people: Fell et al. (2014) explore the issues and propose that different types of demand response 'product offerings' will be needed in order to meet these concerns and to fit with different technologies in the home.

Electric space and water heating emerge as the main end-uses for cold-weather demand response in most homes or small businesses, due to the size and relative flexibility of these loads (Darby and McKenna 2012; Prueggler 2013). However, a single residential space heating load is still small in the grand scheme of things, and a new profession of aggregators has emerged whose function is to guarantee demand reductions from a set of customers and sell this service to the system operator, lessening the risk that individual customers will not be able to respond at a given time. Electricity suppliers (retailers) can themselves act as aggregators for customers with sufficient storage/load-shifting capacity, interval metering and controls, offering a tariff that incentivises them to allow remote control of specified end-uses and/or to carry out some load reduction or load shifting manually.

As noted above, storage heating has already served to flatten demand curves through regular overnight charging and now there is the potential, with the aid of Information and Communication Technology (ICT) and aggregation, for it to operate more flexibly, 'soaking up' abundant wind or solar generation to avoid curtailment and offering fast reserve and frequency regulation services by switching off and on for short periods. Note that system balancing can be carried out at different scales, including community level ${ }^{4}$ or even within a single building. As a small storage heater draws around $1.7 \mathrm{~kW}$ of charge and can store $11.9 \mathrm{kWh}$ (equivalent to 7 hours of charging), with a large heater (such as those used in living rooms) having double that capacity, the economics of storage heating compare favourably with batteries. Hence the claim that the potential for thermal storage at household level is under-recognised, with a risk of missing out on a cost effective short- to mediumterm option for demand response (Sustainability First 2014). The prospective study by DNV KEMA referenced above (2013) estimated that retrofitting the existing storage heaters in $\sim 14 \mathrm{~m}$ EU homes with 'smart storage' (that is, new-generation heaters with digital and remote control) could lead to efficiency savings of around $20 \%{ }^{5}$ and provide up to $51 \mathrm{GW}$ of controllable demand by $2050^{6}$.

\section{Questions of value}

Although residential demand response has developed into a constellation of possible arrangements in terms of the location and ownership of assets, the notice

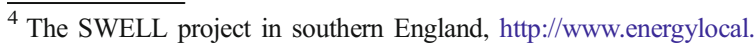
co.uk/projectswell/, offers an example of a trial at community level that includes both storage heating and batteries.

${ }^{5}$ The storage heater manufacturer Glen Dimplex quotes $15 \%$ energy savings and $30 \%$ financial savings during a pilot project in 140 Irish homes.

(http://www.glendimplex.com/news/view/glen_dimplex_group_ launches_revolutionary_quantum_heating_system)

${ }^{6}$ This compares with an estimated $148 \mathrm{GW}$ of demand from all electric space and water heating in $\sim 14 \mathrm{~m}$ EU homes in 2013 (i.e presumably a combination of pure resistive heating, storage heating and heat pumps).
} 
periods required to initiate a response, and the duration and frequency of load-shifting, it is perhaps not surprising that demand response activity is slow to materialise. However, the perceived value of flexibility to lowercarbon electricity systems as a whole is considerable and growing. For example, Strbac et al. (2015) note that 'The impact of the level of flexibility on the system integration cost of renewable generation is very significant.' Enhancing system flexibility [through options including energy storage and demand-side response] reduces system integration cost of renewables by an order of magnitude (page $\mathrm{i}$, their emphasis).

Table 1 offers an illustration of potential value from both traditional/legacy and smart thermal storage heating to the main stakeholders.

To these traditional stakeholders, though, we can add the designers and manufacturers of smart appliances, customer interfaces and communication devices, along with aggregators and third-party agents who operate and maintain communication and data management services. All require some value from the operation of smart storage and somehow value must be 'stacked' in such a way that it is sufficient for each actor, not simply for the system as a whole. So, for example, the smart storage heater may need to be available and usable for ancillary services to the grid as well as for simple nighttime charging; for customers, there may need to be value from responsive controls and attractive design as well as affordable warmth from a more efficient appliance and tariffs that reflect their contribution to system flexibility.

Questions about how demand-side flexibility will be provided, and how costs and benefits will be distributed, are being addressed in trials in many countries, each with its own supply and demand characteristics, infrastructures and regulatory environment (SEDC 2015; Darby et al. 2013). Thermal storage forms one strand in this effort, and some trials of smart distributed thermal storage are already under way, including the NINES project in Shetland, ACCESS in the Isle of Mull (Scotland) and RealValue in Ireland, Germany and Latvia. One, PowerShift Atlantic in New Brunswick, is now complete and claims to have operated effectively with more than 1400 residential and commercial customers and $\sim 17$ MW of load (PowerShift Atlantic 2015).

In what is probably the largest of the current thermal storage trials, RealValue, smart-enabled storage heaters and hot water cylinders are being installed in homes and some commercial buildings in Ireland, Germany and Latvia with the aim of realising value from electricity
Table 1 Some value characteristics of traditional and 'smart'enabled storage heating

\begin{tabular}{|c|c|c|}
\hline & $\begin{array}{l}\text { Traditional storage } \\
\text { heating }\end{array}$ & $\begin{array}{l}\text { 'Smart' storage } \\
\text { heating }\end{array}$ \\
\hline $\begin{array}{l}\text { Value to } \\
\text { customer, } \\
\text { compared } \\
\text { with } \\
\text { non-storage } \\
\text { electric } \\
\text { heating }\end{array}$ & $\begin{array}{l}\text { Warmth. } \\
\text { Lower bills due to } \\
\text { favourable tariffs } \\
\text { for off-peak } \\
\text { electricity but } \\
\text { slow response } \\
\text { from imprecise } \\
\text { controls, which } \\
\text { can only be set a } \\
\text { day ahead in } \\
\text { response to weather } \\
\text { predictions. } \\
\text { Likely to have } \\
\text { excessive } \\
\text { heat in morning and } \\
\text { not enough in } \\
\text { evening }\end{array}$ & $\begin{array}{l}\text { Warmth. } \\
\text { Lower bills due to } \\
\text { favourable dynamic } \\
\text { pricing. } \\
\text { More controllable } \\
\text { than traditional } \\
\text { storage heating, } \\
\text { though still less } \\
\text { responsive than } \\
\text { non-storage } \\
\text { heating. }\end{array}$ \\
\hline $\begin{array}{l}\text { Value to } \\
\text { generator }\end{array}$ & $\begin{array}{l}\text { Enables more use of } \\
\text { baseload plants } \\
\text { during off-peak } \\
\text { periods. }\end{array}$ & $\begin{array}{l}\text { Enables more use of } \\
\text { renewable } \\
\text { generation } \\
\text { whenever it is } \\
\text { available by } \\
\text { absorbing supply. } \\
\text { Could reduce cycling } \\
\text { of thermal } \\
\text { generators. }\end{array}$ \\
\hline $\begin{array}{l}\text { Value to } \\
\text { transmission } \\
\text { system }\end{array}$ & $\begin{array}{l}\text { Reduces transmission } \\
\text { losses and avoids } \\
\text { investment to } \\
\text { upgrade } \\
\text { transmission wires, } \\
\text { by charging } \\
\text { overnight and } \\
\text { reducing peak load. }\end{array}$ & $\begin{array}{l}\text { Reduces transmission } \\
\text { losses and avoids } \\
\text { investment to } \\
\text { upgrade } \\
\text { transmission wires, } \\
\text { by reducing peak } \\
\text { load. }\end{array}$ \\
\hline $\begin{array}{l}\text { Value to } \\
\text { distribution } \\
\text { network }\end{array}$ & $\begin{array}{l}\text { Reduces distribution } \\
\text { losses and avoids } \\
\text { network } \\
\text { reinforcement by } \\
\text { lowering peak } \\
\text { demand. }\end{array}$ & $\begin{array}{l}\text { Reduces distribution } \\
\text { losses and may } \\
\text { avoid or defer } \\
\text { network } \\
\text { reinforcement by } \\
\text { evening out } \\
\text { demand } \\
\text { (though note the } \\
\text { risk of increased } \\
\text { daytime congestion } \\
\text { unless charging is } \\
\text { carefully managed). }\end{array}$ \\
\hline $\begin{array}{l}\text { Value to system } \\
\text { as a whole }\end{array}$ & $\begin{array}{l}\text { Reduces overall } \\
\text { capacity } \\
\text { requirement by } \\
\text { lowering peak } \\
\text { demand. }\end{array}$ & $\begin{array}{l}\text { Reduces overall } \\
\text { capacity } \\
\text { requirement; } \\
\text { offers system } \\
\text { balancing } \\
\text { services through } \\
\text { fast response to } \\
\text { system conditions. }\end{array}$ \\
\hline
\end{tabular}



and regulatory regimes. Ireland has some of the highest wind penetrations and targets in Europe, and McKenna et al. (2014) note the prospect of considerable wind generation curtailment on the "All-island" ${ }^{17}$ system in the near future unless practical storage methods can be employed. Electric space heating is not common in Ireland but there is an estimated potential to retrofit up to 120,000 homes (approximately $5 \%$ of the total) that already have an average of three storage heaters; most of them still controlled to charge overnight by electromechanical clocks, and the rest by a radio signal. ${ }^{8}$

In contrast, the German market is much larger and more diverse, highly deregulated and with a great deal of highly-distributed solar in addition to utility-scale wind. A recent Smart Energy Demand Coalition report (2015) notes plenty of untapped demand-side flexibility in Germany, although demand response and aggregation are already allowed in all German balancing market programmes. As in Ireland, only a small proportion of buildings are electrically heated, but almost all of them use storage heating, with $\sim 3.5 \mathrm{~m}$ devices in $\sim 700,000$ buildings, charged by ripple control. Storage heating in Germany is more common in houses than in apartments ${ }^{9}$ and may be more evenly distributed across socio-economic groups than in the UK and Ireland.

Latvian electricity is supplied via a verticallyintegrated utility that is linked to the large Nordic and Baltic market, Nordpool. District heating networks normally supply heat within urban areas and solid fuel stoves in the countryside. However, gas price increases and concerns about fuel security threaten the heat network business model and may make electric storage heating a viable alternative or supplement to district heating.

While none of the above examples can yet offer definitive findings on the value of demand response with thermal storage, they serve to illustrate how we can expect the type, extent and distribution of value to shift between locations, depending on prevailing usage patterns, regulatory regimes, supply mixes and established heating infrastructures. markets in three systems with contrasting supply mixes

\section{Continuity and change in storage heating}

Storage heating has historically been a relatively simple form of technology, offering a robust service to system operators and a rather inflexible service to users. Smart storage promises more of the same, in that it will carry out the same basic functions of charging at times of relatively plentiful supply and discharging in response to customer needs. In appearance, space requirements and unit costs, it appears to offer plenty of continuity with the past. But smart storage also involves some significant changes, mostly relating to the number and diversity of actors and processes to make possible demand response that will offer enough value to make 'smarting' a worthwhile proposition.

Table 2 compares some attributes of traditional and smart residential storage heating for demand response. Note that the main technical innovation arguably lies with the controls through which heaters will interact with the people who rely on them for warmth, with the supplier/aggregator and with the distribution network and electricity grid. While the appliances can be switched on and off remotely to meet network requirements, this happens within parameters set by the customers - their instructions as to temperatures and timing. Customers' comfort and energy bills will depend on how they operate the controls and this will also influence the extent of system benefits. For example, the temperatures chosen by customers when they programme the new heaters will have an effect on their heating bills and on the amount of flexibility available for the system.

As the table shows, smart storage involves both change and continuity of the basic concept. One of the interesting aspects of researching it will be to discover whether and how a change to smart storage affects heating practices in the home. Is it near- neutral in terms of user activity, so that customers only have to set their preferences for temperature and timing, and the technology will do everything else? Or does smart storage inevitably require changes in how people go about the business of keeping warm and comfortable, and how well they understand their technology and the workings of the electricity system to which they are connected? ${ }^{10}$

\footnotetext{
${ }^{7}$ The Republic of Ireland together with Northern Ireland.

${ }^{8}$ These figures come from the RealValue bid document

${ }^{9}$ Personal communication from RealValue project
}

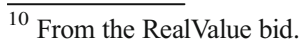


Table 2 Demand response characteristics of traditional and 'smart'-enabled storage heating

\begin{tabular}{|c|c|c|}
\hline & $\begin{array}{l}\text { Traditional storage } \\
\text { heating }\end{array}$ & $\begin{array}{l}\text { 'Smart' storage } \\
\text { heating }\end{array}$ \\
\hline Type of asset & $\begin{array}{l}\text { Electric storage } \\
\text { heaters with } \\
\text { electromechanical } \\
\text { or radio control to } \\
\text { enable night-time } \\
\text { charging. }\end{array}$ & $\begin{array}{l}\text { Electric storage } \\
\text { heaters with digital } \\
\text { controls to enable } \\
\text { 'intelligent demand } \\
\text { shifting and high- } \\
\text { speed demand } \\
\text { interruption', with } \\
\text { charging at times of } \\
\text { abundant/low-cost } \\
\text { supply. }\end{array}$ \\
\hline $\begin{array}{l}\text { Location of } \\
\text { assets }\end{array}$ & $\begin{array}{l}\text { Distributed, often in } \\
\text { clusters (e.g. social } \\
\text { housing; rural } \\
\text { buildings without } \\
\text { access to piped } \\
\text { gas). }\end{array}$ & $\begin{array}{l}\text { Distributed, often in } \\
\text { clusters (e.g. social } \\
\text { housing; rural } \\
\text { buildings without } \\
\text { access to piped } \\
\text { gas). }\end{array}$ \\
\hline $\begin{array}{l}\text { Notice period } \\
\text { required for } \\
\text { load-shifting }\end{array}$ & $\begin{array}{l}\text { Not applicable: heaters } \\
\text { normally charge } \\
\text { during the night, in } \\
\text { response to } \\
\text { electromechanical } \\
\text { control or radio } \\
\text { signals. }\end{array}$ & $\begin{array}{l}\text { Notice to aggregator } \\
\text { can be very short } \\
\text { (e.g. seconds), as } \\
\text { customers do not } \\
\text { need to know when } \\
\text { the appliances are } \\
\text { charging, provided } \\
\text { they have heating } \\
\text { when it is wanted. }\end{array}$ \\
\hline $\begin{array}{l}\text { Duration of } \\
\text { load-shifting }\end{array}$ & Not applicable. & $\begin{array}{l}\text { Can be as long as is } \\
\text { compatible with } \\
\text { customers' control } \\
\text { settings. }\end{array}$ \\
\hline $\begin{array}{l}\text { Frequency of } \\
\text { load-shifting } \\
\text { events }\end{array}$ & Not applicable. & $\begin{array}{l}\text { As dictated by } \\
\text { network and } \\
\text { customer } \\
\text { constraints. }\end{array}$ \\
\hline $\begin{array}{l}\text { Heating } \\
\text { provision }\end{array}$ & $\begin{array}{l}\text { Able to store heat for } \\
\text { up to } \sim 24 \mathrm{~h} \text {; no } \\
\text { thermostatic } \\
\text { control. }\end{array}$ & $\begin{array}{l}\text { Better-insulated and } \\
\text { able to store heat for } \\
\text { roughly twice as } \\
\text { long; thermostatic } \\
\text { control. }\end{array}$ \\
\hline $\begin{array}{l}\text { Metering and } \\
\text { tariff needs }\end{array}$ & $\begin{array}{l}\text { Two-rate meters with } \\
\text { day/night tariffs. }\end{array}$ & $\begin{array}{l}\text { Advanced/smart } \\
\text { meters measuring } \\
\text { consumption at } \\
\text { intervals of } 30 \mathrm{~min} \\
\text { (typically); } \\
\text { sometimes } 15 \mathrm{~min} . \\
\text { 'Static' time-of-use } \\
\text { or 'dynamic' spot- } \\
\text { price-related tariffs. }\end{array}$ \\
\hline $\begin{array}{l}\text { Communication } \\
\text { needs }\end{array}$ & $\begin{array}{l}\text { Radio teleswitch or } \\
\text { electromechanical } \\
\text { control. }\end{array}$ & $\begin{array}{l}\text { Heaters are controlled } \\
\text { by in-home display } \\
\text { hub and } \\
\text { communications } \\
\text { system at household } \\
\text { level, with }\end{array}$ \\
\hline
\end{tabular}

Table 2 (continued)

\begin{tabular}{ll}
\hline $\begin{array}{l}\text { Traditional storage } \\
\text { heating }\end{array}$ & $\begin{array}{l}\text { 'Smart' storage } \\
\text { heating }\end{array}$ \\
& connection to \\
external cloud- \\
based server that \\
monitors aggregat- \\
ed homes. Inter- \\
faces and gateways \\
are market-specific, \\
linked to aggregator \\
platforms.
\end{tabular}

\section{Discussion: some policy, practical and theoretical considerations in relation to smart storage heating}

Smart thermal storage can be viewed as a bridging technology between traditional and transitional electricity systems, potentially able to offer demand response services in supply-led systems as well as absorbing renewable supply when this is available. Less energyefficient than heat pumps, it is less disruptive in one important respect: replacing standard electric resistive heating or traditional storage heaters with new generation heaters is simpler than installing heat pumps. However, smart storage heating is socially and operationally innovative in bringing new actors into the process of heating buildings, such as demand aggregators and ICT specialists; and technically innovative in enabling more flexible management of heating appliances. There are new prospects for interaction between people and technology, individuals and organisations, system and household; and we can expect unforeseen emergent effects from these interactions (for example, arising from attempts to hack into highly-connected systems, or from enterprising Do-It-Yourself adaptations of technology by householders). Yet smart storage relies on the same basic thermal storage function as before, builds on a familiar business model and the appliances look familiar to anyone who has used old-style storage heaters.

Experience with air-conditioning for residential demand response may lead industry practitioners and researchers to think that heating will be similar: a sort of mirror image. Yet heating occupies a different space in the spectrum of possibilities, not least because it has different physiological and social characteristics 
(Wallenborn and Wilhite 2014). A further difference is that air-conditioning has always been supplied through electricity systems and has led to particular, limited types of building design, whereas heating potentially comes from several sources and is used in a wide variety of building types. Also, while air-conditioning is enrolled into demand response programmes primarily to reduce sharp peaks in summer afternoon demand, heating is being called upon to do something more complex, reducing regular peaks but also responding to supply conditions at all times - including the ability to increase load substantially when supply is abundant (Gils 2014).

Smart storage heating is therefore not directly comparable with anything that has gone before-heating practices cannot be seen as equivalent to cooling practices, or to the use of wet appliances - with the possible exception of heat pump adoption, itself a relatively new practice. We can therefore expect evaluation of smart storage heating to shed some new light on the flexibility of activities in the home (Higginson et al. 2014), the knowledge transfer that is needed to adapt to new heating arrangements (Liddell 2015; Topouzi 2015; Wade et al. 2016) and the significance of service expectations, householder activity and technology in shaping demand response (McKenna et al. 2017).

The trials referred to above offer a chance to test out smart thermal storage technology in countries with contrasting climates, housing, demographics, markets and regulatory systems, to record the outcomes in terms of energy use, network services and how customers adapt to smart storage, and to use the findings to model potential outcomes in a range of situations. They are challenging, not least because of the number of actors and processes that have to be harmonised. Early findings from the trials, along with those from other research into residential smart technology, show how significant are the social dimensions to 'smart' forms of familiar technologies. Two examples of this relate to equity and knowledge transfer. Traditionally, storage heating has tended to be 'clustered' in particular types of household, and this is likely to continue, so that we might expect clusters of relatively disadvantaged customers (tenants in small dwellings), and also clusters of wealthier customers, some with solar PV installations who are looking for technology that can store some of what they generate. The types of technology, controls and tariffs on offer will affect perceptions of whether people with storage heating are being 'used' to serve system operators, or partners who manage a shared resource and take a fair share of the benefits (Wolsink 2011). New forms of smart control can also raise equity issues within the home: for example, whether more sophisticated forms of control will concentrate control in the hands of fewer household members than previously (Wilson et al. 2015).

A second issue emerging from the literature on smart technology adoption relates to the significance of knowledge and skills. While we do not yet know much about how people will adapt to managing a new generation of heaters, it is clear that manufacturers, installers, retailers and third party service providers are training for the deployment of smart storage heaters and are not always finding it straightforward. While there is a perception in some parts of the energy industry that the ideal smart technology is one that users do not need to know anything about-one that effectively edits out the user-experience to date with smart metering and heating controls strongly suggests that installers and other 'middle actors' still have an important role in interpreting new technologies to the people who will be using them (Janda and Parag 2013; Darby et al. 2015; Topouzi 2015; Wade et al. 2016; Gram-Hanssen et al. 2016).

\section{Summary and conclusions}

Heating is a major concern for energy policy. While reducing the scale of demand has to be the priority, primarily through building insulation and changes in heating practices, important choices remain about the appliances and systems that can most effectively replace fossil-fuel-burning heaters. As electrifying heating is on the policy agenda in many countries, it is important to explore whether the environmental and operational downside of electrical heating (large extra loads) can be compensated by contributions to system flexibility through demand response. Can resistance heating with storage offer enough value to renewables-powered systems and to customers?

This overview is far from comprehensive but offers some guidance on conditions to be met if smart storage heating is to succeed in the twin tasks of providing customer services and demand response. Historically, storage heating may have succeeded in providing basic 
day-to-night load shifting, but has been less satisfactory in terms of easy-to-control comfort. Smart heat storage with improved end-use efficiency may be described as a bridging technology, familiar to householders and the electricity industry but potentially able to offer novel demand response services. However, implementing what may at first appear a fairly straightforward arrangement for demand response turns out to involve enough new actors and processes to make progress 'over the bridge' quite challenging.

The eventual value to users, system operators and other actors will depend on how the heating is used as well as where it is used. How customers experience and understand this form of heating, the state of their homes (especially whether they are well-insulated or not) and their ability and willingness to assist with demand response are all going to affect the extent to which the heating provides the anticipated network services. Actors in a 'smart' system need to share some understanding of how the system will work and how problems will be resolved, and there are many of these actors: designers and manufacturers for the appliances, communications and interfaces; installers, landlords, maintenance workers and advisers; network and grid operators, energy retailers and third-party energy service providers; and the customers themselves. This complexity points to the importance of knowledge transfer between the parties, and also to the likely need to compromise between different versions of optimisation in order to bring about a workable system. Background material for the smart heater trials being carried out in Germany, Ireland and Latvia also indicates how viability in different countries will be influenced by macro or high-level operating conditions such as climate, regulation, metering and tariffs, settlement, the state of buildings and heating infrastructures.

Finally, the case of smart storage heating raises plenty of questions for future research. For example, in what situations of supply mix and patterns of demand is thermal storage of most value to networks, and what form should it take? What knowledge and skills do customers, installers, network operators and third party service providers need in order to make thermal storage work well for users and system, and how are these transmitted? How is control distributed between users and other stakeholders, and what compromises will be needed in order for each to gain adequate value? When customers generate electricity as well as operating thermal storage, what difference can this make to user and system outcomes? How far is knowledge gained from storage heating applicable to heat pumps and water heating, and vice versa? All these questions and more are relevant for evaluating demand-response-capable heating technologies, to address the complexities of distributed assets, agency and value.

Acknowledgements This paper is based on a conference paper, 'Balancing the system comfortably? Electric storage and residential demand response' presented at BeHAVE 2016, the 4th European conference on behaviour and energy efficiency, September 8-9, 2016, in Coimbra, Portugal. The work for it was carried out as part of the RealValue Project, funded by the European Union's Horizon 2020 research and innovation programme under grant agreement No. 646116. I gratefully acknowledge constructive criticisms and suggestions from reviewers and useful discussions with Sarah Higginson, Stefanie Reiss and other colleagues in the project. Any remaining errors are my own.

\section{Compliance with ethical standards}

Conflict of interest The author declares that she has no conflict of interest.

Open Access This article is distributed under the terms of the Creative Commons Attribution 4.0 International License (http:// creativecommons.org/licenses/by/4.0/), which permits unrestricted use, distribution, and reproduction in any medium, provided you give appropriate credit to the original author(s) and the source, provide a link to the Creative Commons license, and indicate if changes were made.

\section{References}

Asbury, J. G., \& Kouvalis, A. (1976). Electric storage heating: The experience in England and Wales and in the Federal Republic of Germany. Argonne National Laboratory energy and environmental systems division for the U.S. Washington: Energy Research and Development Administration.

BEIS (2016) Energy Consumption in the UK. National Statistics. https:/www.gov.uk/government/statistics/energy-consumptionin-the-uk, Table 3.16.

Bouzarovski, S., \& Petrova, S. (2015). A global perspective on domestic energy deprivation: Overcoming the energy poverty-fuel poverty binary. Energy Research and Social Science, 10, 31-40.

Carlsson-Hyslop, A. (2016). Past management of Energy Demand: Promotion and adoption of electric heating in Britain 19451964. Environment and History, 22(1), 75-102.

Clarke, J., Hand, J., Kim, J-M., Samuel, A. and Svehla, K. (2013) Electricity storage within the domestic sector as a means to enable renewable energy integration within existing electricity networks. Proceedings, BS2013:13th Conference of International Building Performance Simulation Association, Chambéry, France, August 26-28.

Consumer Focus (2012) From devotees to the disengaged. A summary of research into energy consumers' experiences of 
Time of Use tariffs and Consumer Focus's recommendations. CF, London.

Darby, S. J., \& McKenna, E. (2012). Social implications of residential demand response in cool temperate climates. Energy Policy, 49, 759-769.

Darby, S. J., Strömbäck, J., \& Wilks, M. (2013). Potential carbon impacts of smart grid development in six European countries. Energy Efficiency, 6, 725-739.

Darby, S. J., Liddell, C., Hills, D., \& Drabble, D. (2015). Smart metering early learning project: synthesis report. London: For the Department of Energy and Climate Change. https://www. gov.uk/government/uploads/system/uploads/attachment data/file/407568/8_Synthesis_FINAL_25feb15.pdf. Accessed 30 Nov 2016

DNV KEMA (2013) Energy \& Sustainability. Potential for smart electric thermal storage. Contributing to a low carbon electricity system. Report for Glen Dimplex and SSE plc by Raadschelders, J., Sikkema, F. and in t'Groen, B. http://www.dimplex.co.uk/assets/Downloads_PDF/Kema Report.pdf . Accessed 30 Nov 2016

Dimplex Quantum technical specification, 2013, http://www. dimplex.co.uk/products/domestic_heating/installed heating/quantum/quantum/technical_specification.htm

Eyre, N., \& Baruah, P. (2015). Uncertainties in future energy demand in UK residential heating. Energy Policy, 87, 641-653.

Fawcett, T., Eyre, N. and Layberry, R. (2015) Heat pumps and global residential heating. Proceedings, ECEEE summer study, Paper 6-321-15.

Fell, M. J., Shipworth, D., Huebner, G. M., \& Elwell, C. A. (2014). Exploring perceived control in domestic electricity demandside response. Technology Analysis \& Strategic Management, 26(10), 1118-1130.

Frontier Economics and Sustainability First (2014) How could electricity demand-side innovation serve the electricity customer in the longer term? Paper 11 in series 'GB Electricity Demand - realising the resource'. Sustainability First.

Gils, H. C. (2014). Assessment of the theoretical demand response potential in Europe. Energy, 67, 1-18.

Goulden, M., Bedwell, B., Rennick-Egglestone, S., Rodden, T., \& Spence, A. (2014). Smart grids, smart users? The role of the user in demand side management. Energy Research \& Social Science, 2, 21-29.

Gram-Hanssen, K., Heidenstroem, N., Vittersoe, G., Valdorff Madsen, L., \& Hove Jacobsen, M. (2016). Selling and installing heat pumps: Influencing household practices. Building Research and Information. doi:10.1080/09613218.2016.1157420.

Higginson, S., Thomson, M., \& Bhamra, T. (2014). For the times they are a-changin the impact of shifting energy use practices in time and space. Local Environment, 19(5), 520-538.

IpsosMORI (2010) Energy Issues 2009. Survey of British public opinion. https:/www.ofgem.gov.uk/sites/default/files/docs/2010 /06/mori-energyissuesreport-final.pdf

Janda, K., \& Parag, Y. (2013). A middle-out approach for improving energy performance in buildings. Building Research and Information, 41(1).

Liddell, C. (2015). Human factors in energy efficient housing: Insights from a Northern Ireland pocket neighbourhood. Energy Research and Social Science, 10, 19-25.
Maclean, K., Sansom, R., Watson, T., \& Gross, R. (2016). Managing heat system decarbonisation. Comparing the impacts and costs of transitions in heat infrastructure. Final report. London: Imperial College.

McKenna, E., Grünewald, P., \& Thomson, M. (2014). Going with the wind: Temporal characteristics of potential wind curtailment in Ireland in 2020 and opportunities for demand response. IET Renewable Power Generation, 9(1), 66-77.

McKenna, E., Higginson, S., Grünewald, P. and Darby, S.J. (2017) Simulating residential demand response: Improving sociotechnical assumptions in activity-based models of energy demand. Energy Efficiency. doi:10.1007/s12053-017-95254.

National Grid (2016) Power Responsive. Demand side flexibility annual report. http://powerresponsive.com/wpcontent/uploads/2017/01/Power-Responsive-Annual-Report2016-FINAL.pdf

Ofgem. (2015). Insights paper on households with electric and other non-gas heating. London: Office of Gas and Electricity Markets.

PowerShift Atlantic (2015) Final Report for Clean Energy Fund. http://www.powershiftatlantic.com/images/NB_Power_ PSA_EN_Outreach_Report.pdf

Prueggler, N. (2013). Economic potential of demand response at household level-Are central European market conditions sufficient? Energy Policy, 60, 487-498.

Saele, H., \& Grande, O. S. (2011). Demand response from household customers: Experiences from a pilot study in Norway. IEEE Transactions on Smart Grid, 2(1), 90-97.

SEDC (2015) Mapping demand response in Europe today. Smart Energy Demand Coalition.

Strbac, G., Aunedi, M., Pudjianto, D., Teng, F., Djapic, P., Druce, R., Carmel, A., \& Borkowski, K. (2015). Value of flexibility in a decarbonised grid and system externalities of low-carbon generation technologies. For the committee on climate change. London: Imperial College London and NERA Consulting https:/www.theccc.org.uk/wp-content/uploads/2015/10/CCC Externalities_report_Imperial_Final_21Oct20151.pdf.

Sustainability First (2014). The Household Electricity DemandSide \& Participation in the GB Electricity Markets. High level overview. Paper 12 in series 'GB Electricity Demand - realising the resource'. Sustainability First, London.

Topouzi, M. (2015) Deep low-carbon refurbishment challenge: what hasn't worked as designed? Proceedings, ECEEE Summer Study, Paper 5-368-15, pp.1155-1167. 1-6 June, Presqu'île de Giens, France.

Wade, F., Shipworth, M., \& Hitchings, R. (2016). How installers select and explain domestic heating controls. Building Research and Information. doi:10.1080/09613218.2016.11559484.

Wallenborn, G., \& Wilhite, H. (2014). Rethinking embodied knowledge and household consumption. Energy Research and Social Science, 1, 56-64.

Wilson, C., Hargreaves, T., \& Hauxwell-Baldwin, R. (2015). Smart homes and their users: A systematic analysis and key challenges. Personal and Ubiquitous Computing, 19, 463-476.

Wolsink, M. (2011). The research agenda on social acceptance of distributed generation in smart grids: Renewable as common pool resources. Renewable and Sustainable Energy Reviews, $16,822-835$. 